\title{
Modeling Long Range Dependence in Wheat Food Price Returns
}

\author{
Naveen Musunuru ${ }^{1}$ \\ ${ }^{1}$ Hutson School of Agriculture, Murray State University, Murray, Kentucky, USA \\ Correspondence: Department of Agricultue, Oakley Applied Sciences, Murray State University, Murray, KY., \\ 42071, USA. Tel: 1-270-809-4629. E-mail: nmusunuru@ murraystate.edu
}

Received: June 4, 2019

Accepted: August 14, 2019

Online Published: August 18, 2019

doi:10.5539/ijef.v11n9p46

URL: https://doi.org/10.5539/ijef.v11n9p46

\begin{abstract}
The present paper focuses on analyzing the volatility dynamics of wheat commodity based on the presence of long memory. The paper utilizes several econometric tests to identify the presence and magnitude of the fractional difference parameter. Fractional GARCH models, namely FIGARCH and FIEGARCH, are employed to examine the long memory property. Twenty years of wheat daily price data were used to study the long-range dependence. The results reveal that fractional integration is found in the daily wheat price return series. Overall, the FIGARCH model seems a better fit, in describing the time-varying volatility of the commodity adequately, compared to the FIEGARCH model. Food price shocks are likely to persist for a long time for wheat, resulting in higher market risk for producers and increased purchasing costs for consumers.
\end{abstract}

Keywords: long memory, volatility, fractional integration, wheat

\section{Introduction}

Extremely high agricultural commodity price spikes coupled with increased volatilities in recent years resulted in increased market participation from investors and speculators to achieve maximum returns for their investments. Policy makers also redirected their focus recently on commodity markets to deal with issues like regulation of excessive speculative interest, instability of financial markets, and the lack of convergence between futures and cash markets. Volatility analysis is vital for corporations in designing and managing proper hedging programs for commodity risk management. This analysis is equally crucial for investment advisors and hedge fund managers to properly maintain their asset portfolios. Farmers can also benefit from studying the volatility of agricultural commodities in the timing of their marketing decisions. Volatility forecasting in direction and magnitude is essential for traders in pricing the option premiums. Increased volatility in market returns typically is considered as a sign of susceptibility of markets and the overall economy in general to macro events (Hiremath \& Kamaiah, 2010). Higher grain price volatilities increase the food import bills of low-income countries, thereby putting pressure on their balance of payments (FAO, 2011). The purchasing power of poor households, especially in developing countries, is also impacted by increased commodity price volatilities. Finally, volatility studies are important for policymakers to understand various market interrelationships and to establish mechanisms for better handling of market crises emanating from systematic market instability.

Volatility persistence is one of the most common characteristics of financial data and is documented extensively in financial literature (Engle, 1982; Bollerslev, 1986; Alberg et al., 2008; Goudarzi \& Ramanarayanan, 2011). Volatility persistence implies that any unexpected shocks tend to last for a while rather than dying down immediately. Autoregressive Conditional Heteroscedasticity (ARCH) and Generalized ARCH (GARCH) models proposed by Engle (1982), and Bollerslev (1986), are considered as the widely used models to estimate volatility persistence in financial data. Research results further indicate that GARCH formulations perform better in analyzing volatility when compared to the ARCH models. Financial data is considered to display long memory property if the autocorrelations die slowly at a hyperbolic rate (Ding et al., 1993; Baillie et al., 2007). On the contrary, data series is considered displaying short memory, if the autocorrelations disappear quickly (exponential decay) at a small number of lags (stationary ARMA processes). Presence of long memory or long-range dependence in commodity returns would help to understand the nature of agricultural prices. Perfect arbitrage is not possible for the market participants whenever returns display long-range dependence (Mandelbrot, 1971). The existence of such properties would also refute the weak form of efficiency and offer participants opportunities to earn higher profits whenever said assets deviate from their intrinsic value. 
The present literature on long memory can be found in various areas including stock market returns (Andersen et al., 2003; Caporale, Gil-Alana, \& Plastun, 2017; Christensen et al., 2007; Hiremath \& Kamaiah, 2010; Onour, 2010); currency exchange returns (Andersen \& Bollerslev, 1997; Jayasinghe et al., 2014); real estate market returns (Wilson \& Okunev, 1999; Stevenson, 2002) and futures market returns (Barkoulas et al., 1997; Kang et al., 2009), whereas limited work has been done in the area of agricultural commodities (Hyun-Joung, 2008; Mann et al., 2012). One of the primary motivations for this study is to better understand recent increases in world food price volatilities, especially wheat. Even though historical wheat prices suggest that wheat has experienced volatile peaks about once every decade since the 1970s, the frequency of such volatile peaks has increased in recent years. One of the critical years to study the wheat price volatility is the year of 2008. Wheat futures prices for a continuous contract began that year at $\$ 9.15$ per bushel, reached an unprecedented high of $\$ 12.80$ per bushel on February 27, 2008, but subsequently witnessed a steep decline and by the end of the year, wheat prices settled around $\$ 4.50$ per bushel (Figure 1). Minot (2012) compared the price volatility of major grains during 1980-2006 with that of 2007-10 and concluded that international rice and wheat volatilities roughly doubled for the period. Recent increased volatility in commodity markets, especially in food grains, is fueled by increased production costs, unstable annual production numbers stemming from frequent droughts and floods, and continually diminishing global grain stocks due to population pressures. Continued higher volatility in agricultural commodity prices in the near future increases risk for both producers and end users.

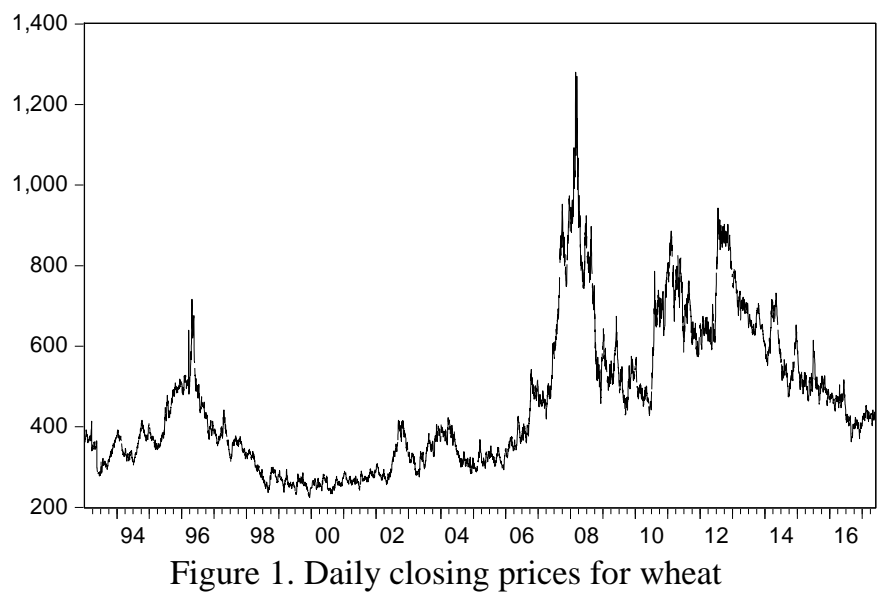

The focus of this study is to model long-range dependence in wheat, using fractionally integrated conditional volatility models. Wheat was specifically chosen for this paper as it is one of the major agricultural commodities, a staple food for hundreds of millions of people across the globe and is actively traded on the world commodity exchanges. The analysis of the paper starts by inspecting the autocorrelation of wheat returns. Later, we test the long-range dependence and measure the presence of fractional integration in the data series. Finally, the paper employs both Fractionally Integrated and Fractionally Integrated Exponential GARCH models to understand wheat volatility behavior.

\section{Methodology}

\subsection{FIGARCH}

Conventional GARCH models face limitations in capturing volatility accurately whenever autocorrelations exhibit slow decay in conditional variance. Hence, the paper employs FIGARCH and FIEGARCH volatility models. Just like traditional GARCH models, FIGARCH models incorporate volatility clustering and capture the properties of asset returns. Additionally, by measuring the extent of fractional integration $(d)$ parameter, these models quantify long memory features of the data, where external shocks diminish slowly but are considered not permanent.

For a weakly stationary data, if the autocorrelation function (ACF) $\rho($.) displays a hyperbolic decay, then the long memory can be represented as:

$$
\rho(k) \square C_{1} k^{2 d-1} \text { as } k \rightarrow \infty, C_{1} \neq 0,0<d<0.5
$$

$d$ represents the long memory property or extent of fractional integration, and it controls the rate of decay of the correlations. 
On the contrary, the data series exhibit short memory if $-0.5<d<0$.

In the standard GARCH $(p, q)$ model, the variance is shown as a distributed lag of past squared innovations:

$$
\sigma_{t}^{2}=\omega+\sum_{i=1}^{p} \alpha_{i} \varepsilon_{t-i}^{2}+\sum_{j=1}^{q} \beta_{i} \sigma_{t-j}^{2} \equiv \omega+\alpha(L) \varepsilon_{t}^{2}+\beta(L) \sigma_{t}^{2}
$$

Where $\sigma^{2}$ is the conditional variance of $\varepsilon_{t} ; \omega>0 ; \alpha_{i} \geq 0 ; \beta_{j} \geq 0 ; L$ denotes the delay or backshift operator. Rearranging terms in the above equation leads to:

$$
[1-\alpha(L)-\beta(L)] \varepsilon_{t}^{2}=\omega+(1-\beta(L)) v_{t}
$$

Where $\alpha(L), \beta(L)$ are polynomials in $L$ and $v_{t} \equiv \varepsilon_{t}^{2}-\sigma_{t}^{2}, \varepsilon_{t}^{2}$ is the squared error of the GARCH process. If the roots of $[1-\alpha(L)-\beta(L)]$ and $[1-\beta(L)]$ lie outside the unit circle, then $\varepsilon_{i}^{2}$ shows stability and covariance stationarity.

Baillie, Bollerslev, and Mikkelsen (1996) introduced Fractionally Integrated GARCH, or FIGARCH $(p, d, q)$, class of models which can be specified as:

$$
\phi(L)(1-L)^{d} \varepsilon_{t}^{2}=\omega+[1-\beta(L)] v_{t}
$$

Where $\phi(L)=[1-\alpha(L)-\beta(L)](1-L)^{-1} ; \phi(L)$ and $\beta(L)$ are polynomial in $L$ of orders $p$ and $q$ respectively. The parameters $\omega, \beta, d$ are to be estimated. When $d=0$, the FIGARCH model changes to traditional GARCH model, and when $d=1$, it changes to the IGARCH model. The coefficients in $\phi(L)$ and $\beta(L)$ capture short-run dynamics, when $0<d<1$, whereas the fractional difference parameter $d$, captures the long run volatility characteristics.

Changing $v_{t}$ in the above equation, and subsequently, the equation becomes:

$$
[1-\beta(L)] \sigma_{t}^{2}=\omega+\left[1-\beta(L)-\phi(L)(1-L)^{d}\right] \varepsilon_{t}^{2}
$$

The variance equation then specified as:

With

$$
\sigma_{t}^{2}=\omega[1-\beta(1)]^{-1}+\eta(L) \varepsilon_{t}^{2}
$$

With

$$
\begin{aligned}
& \eta(L)=\left[1-[1-\beta(L)]^{-1} \phi(L)(1-L)^{d}\right] \\
= & \eta_{1} L+\eta_{2} L+\ldots \text { and } \eta_{k} \geq 0 ; k=1,2, \ldots ., n
\end{aligned}
$$

The long memory parameter $(d)$ provides essential information about the pattern and magnitude with which shocks occur to the volatility process. For values of $d>1$, the conditional variance $\sigma^{2}$ becomes explosive, and impulsive response becomes undefined.

\subsection{FIEGARCH}

To assure that a FIGARCH model is both stationary and its conditional variance, $\sigma_{t}^{2}$, remains positive, some constraints need to be forced on the coefficients of the model. Accordingly, we employ the Fractionally Integrated EGARCH (FIEGARCH) model proposed by Bollerslev and Mikkelsen (1996). The model is specified as:

$$
\phi(L)(1-L)^{d} \ln \left(\sigma_{t}^{2}\right)=\omega+\sum_{j=1}^{q}\left(b_{j}\left|x_{t-j}\right|+\gamma_{j} x_{t-j}\right)
$$

Where $x_{t}$ is the standardized residual, $\gamma_{j} \neq 0$ shows the presence of leverage effects. With any unexpected shocks, if the bad news creates a lasting impact on volatility than positive news, then it is considered to have an asymmetric impact on volatility.

\section{Data}

Daily closing prices for wheat futures contract (size: 5000 bushels) have been used in the study to understand the long memory property. The study specifically examines the period between January 2, 1993, and May 16, 2017, to explore the long memory property in wheat, resulting in a study sample of 6353 observations. Five contract months are available for wheat futures for a single year (March, May, July, September, and December). Because of the contract expiration problems, price data is collected for the most actively traded contract months using volume crossover method. Returns are computed from the price series by calculating the first difference of logarithm of closing market prices for wheat for two consecutive trading days. 


\section{Results}

The top left panel of figure 2 shows the daily returns for the study period, whereas the top right panel shows the histogram of returns for wheat. Closer examination of the daily returns, reveals the return series exhibits volatility clustering property, where any unusual levels of volatility tend to persist or continue for some time before changing to a different level. One of the unique features from figure 2 is that the volatility of wheat is significantly high beginning in early 2008. Volatility is vital for market participants because periods of high volatility bring larger profit margins to the investment portfolios when compared to low volatility periods. The bottom left panel of figure 2 shows boxplot of returns, and the right panel shows the QQ plot of returns. Plotting boxplots help researchers in assessing whether the data is symmetric or skewed. Boxplot results in figure 2 show that the longer part of the box is to the left of the median, implying that the data is skewed left. Q-Q plot in the graph shows empirical percentiles of the wheat return data against the same theoretical percentiles of a t-distribution. The graphical results show that the wheat returns are fat-tailed compared to normal distribution.

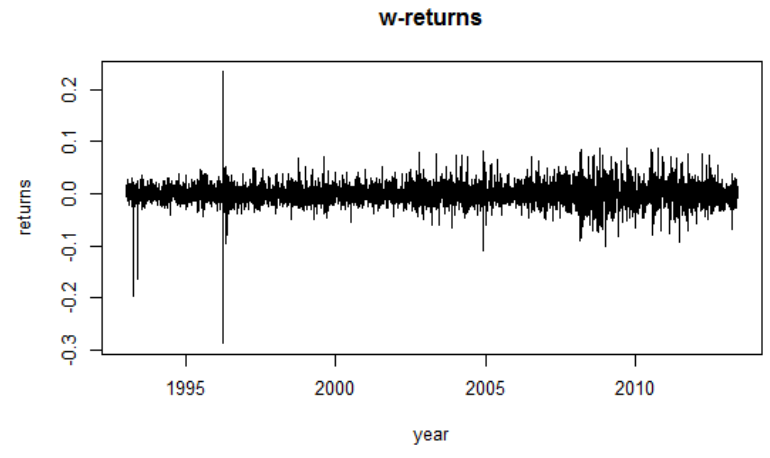

Boxplot of returns

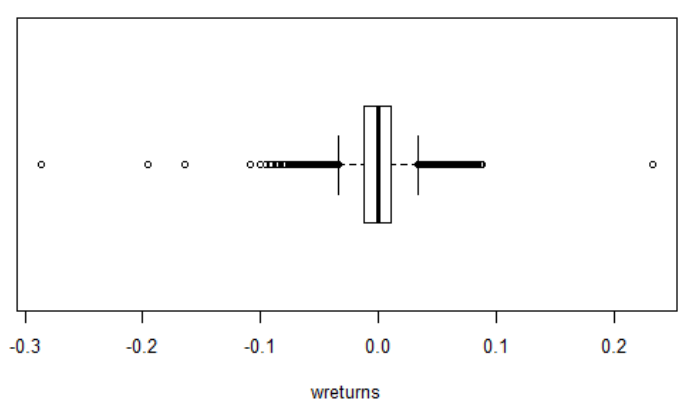

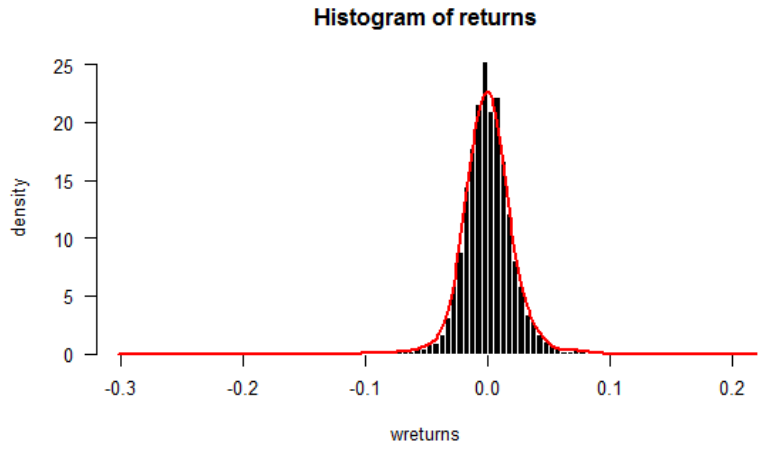

QQ plot of returns

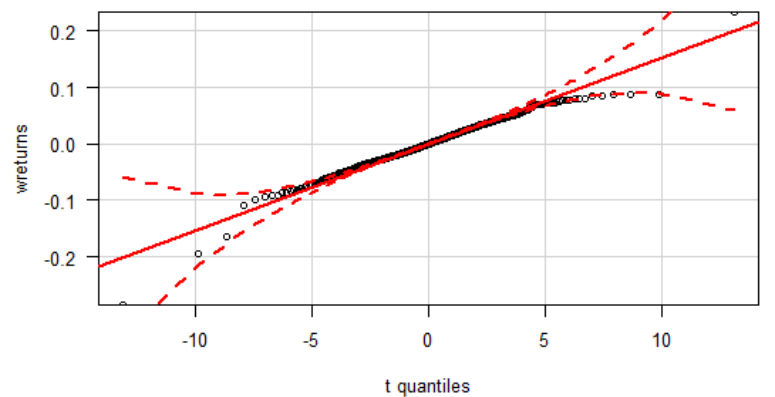

Figure 2. Wheat daily returns and tail distribution

The descriptive statistics of wheat daily futures returns along with a normality test and a test for the presence of homoscedasticity are represented in Table 1 . The results show that the average daily returns for wheat is close to zero, but is positive for the study period. The standard deviation of the daily returns for wheat is $2.04 \%$, which implies the underlying volatility. Presence of negative skewness in the data shows the influences of large negative returns are higher than those of the positive returns. The data series is considered as leptokurtic because of its high kurtosis value with distributions exhibiting fat tails and excess peakedness at the mean. Jarque-Bera statistics, which measures the deviation of the third and fourth central moments from the normal distribution, are significant. The ARCH test reveals that homoscedasticity in returns is rejected at a $1 \%$ level, indicating that volatility in wheat changes through time. Based on the summary of results, it is evident that GARCH models would perform better in analyzing volatility and long memory property in wheat returns. 
Table 1. Summary statistics for Wheat futures returns

\begin{tabular}{cc}
\hline Average & 0.000169 \\
\hline Daily Minimum & -0.2861 \\
Daily Maximum & 0.233 \\
Standard Deviation & 0.0204 \\
Skewness & -0.4498 \\
Kurtosis & 17.63 \\
Excess Kurtosis & 14.63 \\
Jarque-Bera (JB) & $46064.23^{* *}$ \\
ADF Test & $-29.89^{* *}$ \\
ARCH Test & $616.24(0.000)$ \\
\hline
\end{tabular}

Note. Numbers in parenthesis for the ARCH test are the corresponding probabilities.

The presence of long memory in wheat is tested first by using an informal approach of a visual examination of autocorrelation decay rate and later by employing two formal tests for its presence. The two formal tests used in the paper include Modified Rescale Range (R/S) static developed by Lo (1991) and the GPH test developed by Geweke \& Porter-Hudak (1983). Finally, econometric volatility model results (FIGARCH and FIEGARCH) for the long memory in wheat are discussed.

Figure 3 shows the autocorrelation function of absolute wheat daily returns, and the graph shows that the autocorrelation is persistent and significant even at higher lag length (200 lags). Traditional ARMA processes have a short memory, and as a result, its autocorrelation function decays exponentially. On the other hand, the ACF dies more slowly than the theoretical autocorrelation at long lags. The traditional stationary ARMA processes generally produce an excessive number of parameters for model estimation, especially when the autocorrelation decay date is slow. Based on figure 4 (straight line), and the empirical results (not reported), the suitable AR model for describing the wheat data series is the AR (29) model. The results show that 29 autoregressive coefficients were indeed required to analyze the long-range dependence in data.

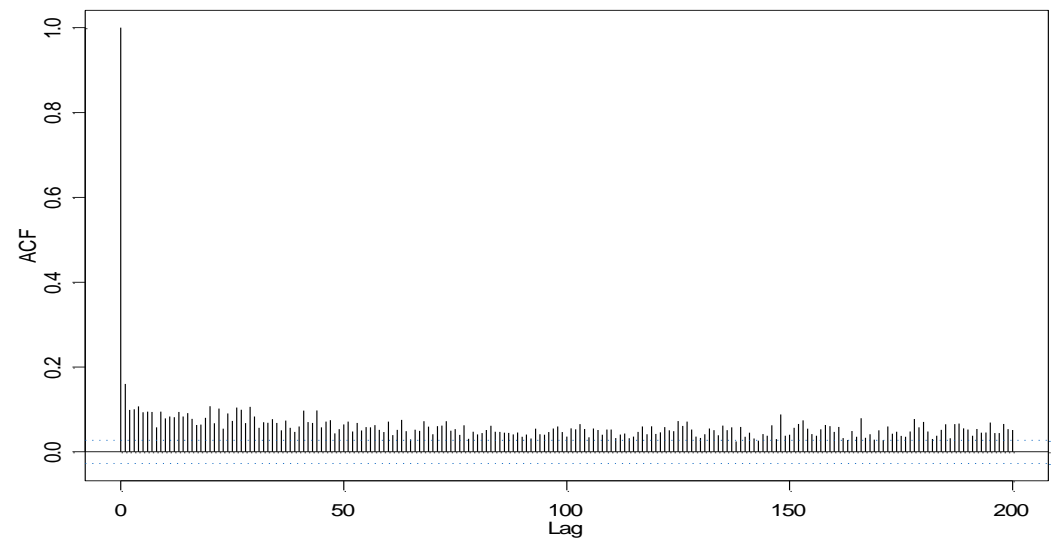

Figure 3. ACF of absolute daily returns for wheat (200 lags)

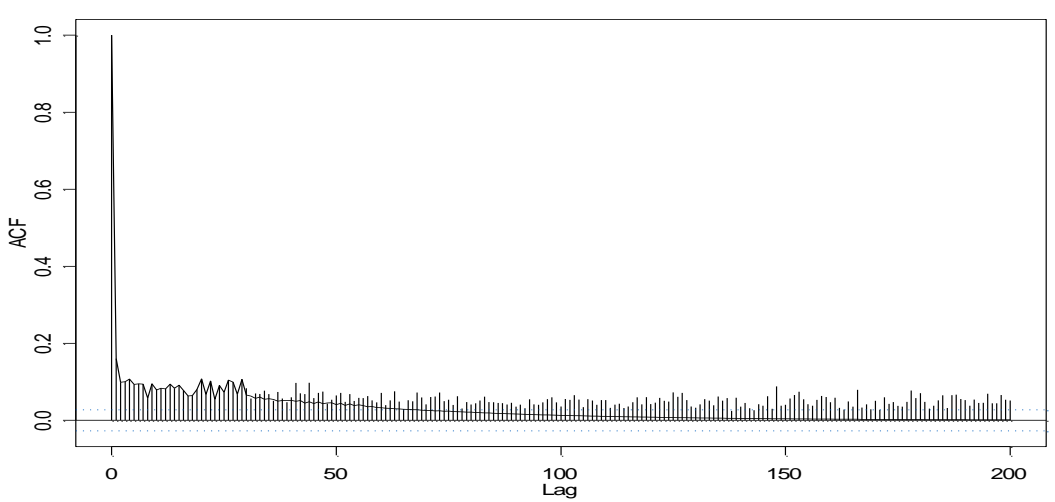

Figure 4. Comparison of AR(29) process with the observed ACF 


\subsection{R/S Statistic}

Initially conceptualized by Hurst (1951), later updated independently by Mandelbrot (1972) and Lo (1991), the $\mathrm{R} / \mathrm{S}$ statistic is considered to be the best measure for testing the presence of long memory. Lo (1991) reported that the original statistic does not distinguish between long and short memory. Lo recommended an updated statistic in order to account for short-range dependence in time series:

$$
Q_{T}=\frac{1}{\sigma_{T}(q)}\left[\max _{1 \leq k \leq T} \sum_{j=1}^{k}\left(Y_{j}-\bar{Y}_{T}\right)-\min _{1 \leq k \leq T} \sum_{j=1}^{k}\left(Y_{j}-\bar{Y}_{T}\right)\right]
$$

Where $\sigma_{T}$ is the long run variance, $\mathrm{T}$ is the sample size. For a financial data series $\mathrm{Y}$, by comparing the realized value, $Y_{j}$, to its mean $\bar{Y}_{T}$, we analyze the range of the variation. The above statistic incorporates short memory in the data series, robust to non-normality and heteroscedasticity, and also identifies if long memory exists in it. R/S statistic is highly sensitive to its order of truncation $(q)$. If $q$ is small, then the statistic does not consider the autocorrelation process. On the other hand, if $q$ becomes big, it considers for any form of autocorrelation. If $q$ equals zero, then Lo's modified R/S statistic changes to Hurst's statistic. By default, the bandwidth $q$ is computed for the modified R/S statistic by using the formula $\left[4(T / 100)^{1 / 4}\right]$. In this study, besides the default formula, we also considered various values of $q: 5,10,15,20$, and 50 . The results are reported in Table 2 .

Table 2. Lo modified R/S test statistic for Wheat returns

\begin{tabular}{cc}
\hline Order & $Q_{T}$ Statistic \\
\hline 5 & $5.6611^{* *}$ \\
$10^{+}$ & $4.9767^{* *}$ \\
15 & $4.5214^{* *}$ \\
20 & $4.1856^{* *}$ \\
50 & $3.1082^{* *}$ \\
\hline
\end{tabular}

Note. ${ }^{*} *$ indicate significance at $1 \%$ confidence level, ${ }^{+}$indicate default $q$ value.

The results in the above table indicate that $\mathrm{R} / \mathrm{S}$ test statistic values are highly significant at a $1 \%$ confidence level at various levels of $q$ and the wheat daily return series display a strong dependent structure

\subsection{GPH Test}

Presence of long memory can also be tested by using the semi-parametric approach proposed by Geweke and Porter-Hudak (1983). The GPH method was developed on the behavior of the spectral density around low frequencies. Following Zivot and Wang (2006), for a fractionally integrated process $\left(y_{t}\right)$, the spectral density can be shown as:

$$
f(\omega)=\left[4 \sin ^{2}\left(\frac{\omega}{2}\right)\right]^{-d} f_{\vartheta}(\omega)
$$

Where $\omega$ is the Fourier frequency, and $f_{\vartheta}(\omega)$ is the spectral density corresponding to $u_{t}$. The fractional difference parameter $d$ can be estimated by the following spectral regression:

$$
\ln f\left(\omega_{j}\right)=\beta-d \ln \left[4 \sin ^{2}\left(\frac{\omega_{j}}{2}\right)\right]+e_{j}
$$

For $j=1,2, \ldots . n_{f}(T)$. For the null hypothesis of no long memory $(d=0)$, the test statistic is

$$
t_{d=0}=d \cdot\left(\frac{\pi^{2}}{6 \sum_{j=1}^{n_{f}}\left(X_{j}-\bar{X}\right)^{2}}\right)^{-1 / 2}
$$


Where $X_{j}=\ln \left[4 \sin ^{2}\left(\frac{\omega_{j}}{2}\right)\right]$ and $\bar{X}$ is the sample mean of $X_{j}$.

We selected different $\propto$ values $\left(T^{0.45}, T^{0.50}, T^{0.55}\right.$, and $T^{0.75}$ ) to assess the stability of model estimation as the periodogram ordinates change. Table 3 shows the results of the GPH parameter estimation values.

The parameter values obtained from the spectral technique indicate the presence of long memory as their values lie within the theoretical value $(0<d<0.5)$ for the daily wheat returns. For all the various levels of periodogram ordinates used in the present paper, the parameter values are significant at a $1 \%$ confidence level.

Table 3. GPH estimation of fractional integration parameter for Wheat

\begin{tabular}{|c|c|}
\hline$n_{f}(T)$ & FI Parameter \\
\hline \multirow[t]{2}{*}{$T^{0.45}$} & $0.3517^{* *}$ \\
\hline & $(3.250)$ \\
\hline \multirow[t]{2}{*}{$T^{0.50+}$} & $0.4022^{* *}$ \\
\hline & (4.778) \\
\hline \multirow[t]{2}{*}{$T^{0.55}$} & $0.3516^{* *}$ \\
\hline & (5.309) \\
\hline \multirow[t]{2}{*}{$T^{0.75}$} & $0.1813^{* *}$ \\
\hline & (6.779) \\
\hline
\end{tabular}

Note. $T$ is the number of observations, $n_{f}(T)$ is the number of periodogram ordinates, t-statistic for $d$ is reported in parenthesis, ${ }^{* *}$ indicates significance at $1 \%$ level, ${ }^{+}$show the default value.

Table 4. Estimation of $\mathrm{FI}(\mathrm{E}) \mathrm{GARCH}(1, \mathrm{~d}, 1)$ processes for Wheat daily volatility

\begin{tabular}{lcc}
\hline Parameter & FIGARCH (1,d,1) & FIEGARCH (1,d,1) \\
\hline$\mu_{0}$ & -0.000259 & 0.000279 \\
$\omega$ & $(-1.082)$ & $(1.137)$ \\
& $0.000024^{* *}$ & $-0.1879^{* *}$ \\
$\alpha$ & $(7.17)$ & $(-10.63)$ \\
& $0.3582^{* *}$ & $0.1645^{* *}$ \\
$\beta$ & $(8.88)$ & $(12.96)$ \\
& $0.6154^{* *}$ & $0.5044^{* *}$ \\
$d$ & $(16.01)$ & $(4.14)$ \\
& $0.3911^{* *}$ & $0.4383^{* *}$ \\
$\gamma$ & $(6.76)$ & $(20.65)$ \\
& & $0.1051^{* *}$ \\
$Q_{12}$ & & $(12.77)$ \\
$Q_{12}^{2}$ & 9.297 & 9.071 \\
& $(0.67)$ & $(0.69)$ \\
ARCH-LM Test & 2.663 & 3.318 \\
AIC & $(0.99)$ & $(0.99)$ \\
\hline
\end{tabular}

Note. $\alpha$ and $\beta$ represents the ARCH and GARCH coefficients respectively. $d$ corresponds to the fractional difference parameter and $\gamma$ represents leverage coefficient for the FIEGARCH model. $t$ statistics are shown in the parentheses below coefficient estimates. Significance is represented at $1 \%$ level. AIC represents Akaike information criteria. $Q_{12}$ and $Q_{12}^{2}$ are the Ljung-Box statistics.

We estimated FIGARCH and FIEGARCH processes using the BFGS maximization method to verify two long memory test results and to model the volatility dynamics of wheat returns. Table 4 reports the results of fractionally integrated GARCH models for wheat returns. The GARCH coefficient $(\beta)$ is significant at $1 \%$ level, suggesting that the conditional variance depends upon its own lagged values for wheat. Generally, a large sum of $\alpha$ and $\beta$ would infer that substantial positive or negative returns will result in future forecasts of the variance to remain high for a sustained period (Brooks, 2014). Accordingly, the results show that the summation of coefficients $(\alpha)$ and $(\beta)$ in Table 4 is close to one, indicating that the volatility of the wheat returns shows 
persistence over time. The long memory parameter values, $d$, are equal to 0.3911 and 0.4383 for FIGARCH and FIEGARCH models, respectively. The null hypothesis of no long memory has been rejected for, $d$, and the values are found significant at a 1\% significance level for both FIGARCH and FIEGARCH models. Significant fractional integration parameter values imply that any shocks to volatility decay slowly at a hyperbolic rate than the typical fast decay (exponential rate). The leverage coefficient value $(\gamma=0.1051)$ is positive and significant for the FIEGARCH model indicating asymmetry in the data series with positive shocks carrying a more significant impact over adverse shocks for wheat.

Additional tests are performed to understand better which GARCH process provides the most parsimonious fit and is successful in analyzing the conditional variance of wheat returns. The diagnostic results show that both the FIGARCH and FIEGARCH models adequately capture the financial characteristics of the data series and confirm no residual ARCH effects remain in the estimated models. The Ljung-Box Q statistics, which test the remaining autocorrelation in the residuals and squared residuals are insignificant. The insignificance of the Q statistics shows that the GARCH models are appropriately modeled. The Q statistics in table 4 clearly shows the models are properly specified. The optimal model selection criterion for the GARCH specifications is based on the Akaike's (AIC) criteria. The model rankings reveal FIGARCH $(1, \mathrm{~d}, 1)$ is the preferred model for wheat and is successful in capturing the time series characteristics of the returns.

\section{Conclusion}

By applying fractionally integrated GARCH models, the present study aims at analyzing the presence of long-range dependence in daily wheat returns. Application of FI(E)GARCH models represent the recent advances in the field of empirical finance, especially in volatility modeling. Relatively similar fractional integrated parameter values and diagnostic test results indicate that the models well describe volatility in wheat. The model selection criteria suggest that the FIGARCH $(1, d, 1)$ model outperformed $\operatorname{FIEGARCH}(1, d, 1)$ in describing time-varying return volatility behavior in wheat. The research results have important practical applications for the agribusiness sector, especially in pricing wheat option premiums, developing effective wheat hedge ratios and for optimal portfolio allocation decisions. While this study is confined to model the long-range dependence for only one food commodity, further studies are needed to analyze the presence, and magnitude of long-range dependence in other agricultural products and at different data time frequencies, to better understand their volatility behavior.

\section{References}

Alberg, D., Shalit, H., \& Yosel, R.(2008). Estimating stock market volatility using asymmetric GARCH models. Applied Financial Economics, 18(15), 1201-1208. https://doi.org/10.1080/09603100701604225

Andersen, T. G., \& Bollerslev, T. (1997). Intraday periodicity and volatility persistence in financial markets. Journal of Empirical Finance, 4(2-3), 115-158. https://doi.org/10.1016/S0927-5398(97)00004-2

Andersen, T. G., Bollerslev, T., Diebold, F. X., \& Labys, P. (2003). Modeling and forecasting realized volatility. Econometrica, 71(2), 579-625. https://doi.org/10.1111/1468-0262.00418

Baillie, R. T., Bollerslev, T., \& Mikkelsen, H. O. (1996). Fractionally integrated generalized autoregressive $\begin{array}{lllll}\text { conditional heteroskedasticity. Journal of } & \text { Econometrics, } & 74(1), & 3-30 .\end{array}$ https://doi.org/10.1016/S0304-4076(95)01749-6

Baillie, R. T., Han, Y., Myers, R., \& Song, J. (2007). Long memory models for daily and high-frequency commodity futures returns. Journal of Futures Markets, 27(7), 643-668. https://doi.org/10.1002/fut.20267

Barkoulas, J., Labys, C. W., \& Onochie, J. (1997). Fractional dynamics in international commodity prices. $\begin{array}{lllll}\text { Journal of } & \text { Futures } & \text { Markets, } & 17(2), & 161-189 .\end{array}$ https//doi.org/10.1002/(SICI)1096-9934(199704)17:2<161::AID-FUT2>3.0.CO;2-H

Bollerslev, T. (1986). Generalized autoregressive conditional heteroskedasticity. Journal of Econometrics, 31(3), 307-327. https://doi.org/10.1016/0304-4076(86)90063-1

Bollerslev, T., \& Mikkelsen, H. O. (1996). Modeling and pricing long memory in stock market volatility. Journal of Econometrics, 73(1), 151-184. https://doi.org/10.1016/0304-4076(95)01736-4

Brooks, C. (2014). Introductory Econometrics for Finance. NY: Cambridge University Press. https://doi.org/10.1017/CBO9781139540872

Caporale, G. M., Gil-Alana, L. A., \& Plastun. O. (2017). Long memory and data frequency in financial markets. DIW Berlin discussion paper no. 1647. https://dx.doi.org/10.2139/ssrn.2929524 
Christensen, B. J., Nielsen, M. O., \& Zhu, J. (2007). Long memory in stock market volatility and the volatility-in-mean effect: The FIEGARCH-M model. CREATES research paper: 2007-10, University of Aarhus, Denmark. https://doi.org/10.2139/ssrn.1150049

Ding, Z., Granger, C. W. J., \& Engle, R. F. (1993). A long memory property of stock market returns and a new model. Journal of Empirical Finance, 1(1), 83-106. https://doi.org/10.1016/0927-5398(93)90006-D

Engle, R. F. (1982). Autoregressive conditional heteroskedasticity with estimates of the variance of U.K. inflation. Econometrica, 50(4), 987-1008. https://doi.org/10.2307/1912773

FAO. (2011). Food Prospects and Crop Situation. October 2011. Rome.

Geweke, J., \& Porter-Hudak, S. (1983). The estimation and application of long memory time series models. Journal of Time Series Analysis, 4(4), 221-238. https://doi.org/10.1111/j.1467-9892.1983.tb00371.x

Goudarzi, H., \& Ramanarayanan, C. S. (2011). Modeling asymmetric volatility in the Indian stock market. International Journal of Business and Management, 6(3), 221-231. https://doi.org/10.5539/ijbm.v6n3p221

Hiremath, G. S., \& Kamaiah, B. (2010). Long memory in stock market volatility: Indian evidences. Artha Vijnana, 52(4), 332-345. https://doi.org/10.21648/arthavij/2010/v52/i4/115316

Hurst, H. E. (1951). Long term storage capacity of reservoirs. Transactions of the American Society of Civil Engineers, 116, 770-799.

Hyun-Joung, J. (2008). A long memory conditional variance model for international grain markets. Journal of Rural Development/Nongchon-Gyeongje, 31(2), 1-23. Retrieved from http://ideas.repec.org/a/ags/jordng/45654.html

Jayasinghe, P., Tsui, A. K. C., \& Zhang, Z. (2014). New estimates of time-varying currency betas: A trivariate BEKK approach. Economic Modelling, 42, 128-139. https://doi.org/10.1016/j.econmod.2014.06.003

Kang, S. H., Kang, S. M., \& Yoon, S. M. (2009). Forecasting volatility of crude oil markets. Energy Economics, 31(1), 119-125. https://doi.org/10.1016/j.eneco.2008.09.006

Lo, A. W. (1991). Long term memory in stock market prices. Econometrica, 59(5), 1279-1313. https://doi.org/10.2307/2938368

Mandelbrot, B. (1971). When can price be arbitraged efficiently? A limit to the validity of the random walk and martingale models. Review of Economics and Statistics, 53(3), 225-236. https://doi.org/10.2307/1937966

Mandelbrot, B. (1972). Statistical methodology for non-periodic cycles: From the covariance to R/S analysis. Annals of Economic and Social Measurement, 1, 259-290.

Mann, J. M., Epperson, J., \& Escalante, C. (2012). The role of long memory in hedging strategies for Canadian commodity futures. Journal of Agribusiness, 30, 201-224.

Minot, N. (2012). Food price volatility in Africa. Has it really occurred? IFPRI discussion paper 01239, Washington, USA. https://doi.org/10.2139/ssrn.2197406

Onour, I. A. (2010). North Africa stock markets: Analysis of long memory and persistence of shocks. International Journal of Monetary Economics and Finance, 3(2), 101-111. https://doi.org/10.1504/IJMEF.2010.031231

Stevenson, S. (2002). An examination of volatility spillovers in REIT returns. Journal of Real Estate Portfolio Management, 8(3), 229-238.

Wilson, P. J., \& Okunev, J. (1999). Long term dependencies and long run non-periodic co-cycles: Real estate and stock markets. Journal of Real Estate Research, 18(2), 257-278.

Zivot, E., \& Wang, J. (2006). Modeling Financial Time Series with S-Plus. Springer Science and Business Media, New York, NY.

\section{Copyrights}

Copyright for this article is retained by the author(s), with first publication rights granted to the journal.

This is an open-access article distributed under the terms and conditions of the Creative Commons Attribution license (http://creativecommons.org/licenses/by/4.0/). 